\title{
Magnetocaloric effect in heavy rare-earth elements doped Fe-based bulk metallic glasses with tunable Curie temperature
}

\author{
Jiawei Li, ${ }^{1,2}$ Juntao Huo, ${ }^{1,2}$ Jiayan Law, ${ }^{3}$ Chuntao Chang, ${ }^{1,2, a)}$ Juan Du, ${ }^{1,2, a)}$ Qikui Man, ${ }^{1,2}$ \\ Xinmin Wang, ${ }^{1,2}$ and Run-Wei $\mathrm{Li}^{1,2}$ \\ ${ }^{1}$ Key Laboratory of Magnetic Materials and Devices, Ningbo Institute of Materials Technology \& \\ Engineering, Chinese Academy of Sciences, Ningbo, Zhejiang 315201, China \\ ${ }^{2}$ Zhejiang Province Key Laboratory of Magnetic Materials and Application Technology, Ningbo Institute of \\ Materials Technology \& Engineering, Chinese Academy of Sciences, Ningbo, Zhejiang 315201, China \\ ${ }^{3}$ Department of Applied Physics, Chalmers University of Technology, SE-412 96 Göteborg, Sweden
}

(Received 8 July 2014; accepted 25 July 2014; published online 12 August 2014)

\begin{abstract}
The effects of heavy rare earth (RE) additions on the Curie temperature $\left(T_{C}\right)$ and magnetocaloric effect of the Fe-RE-B-Nb ( RE = Gd, Dy and Ho) bulk metallic glasses were studied. The type of dopping RE element and its concentration can easily tune $T_{C}$ in a large temperature range of $120 \mathrm{~K}$ without significantly decreasing the magnetic entropy change $\left(\Delta S_{M}\right)$ and refrigerant capacity $(R C)$ of the alloys. The observed values of $\Delta S_{M}$ and $R C$ of these alloys compare favorably with those of recently reported Fe-based metallic glasses with enhanced $R C$ compared to $\mathrm{Gd}_{5} \mathrm{Ge}_{1.9} \mathrm{Si}_{2} \mathrm{Fe}_{0.1}$. The tunable $T_{C}$ and large glass-forming ability of these RE doped Fe-based bulk metallic glasses can be used in a wide temperature range with the final required shapes. (C) 2014 AIP Publishing LLC.
\end{abstract}

[http://dx.doi.org/10.1063/1.4892431]

\section{INTRODUCTION}

Magnetic refrigeration based on magnetocaloric effect (MCE), exhibits great merits, such as relatively high energy efficiency and environmental friendliness, making it a potential alternative to the conventional vapor compression refrigeration technology. ${ }^{1,2}$ The MCE is manifested as the adiabatic temperature change of a magnetic material upon the application of an external magnetic field, and usually quantified by isothermal magnetic entropy change $\left(\Delta S_{M}\right){ }^{3}$ Generally, for application of active regenerative refrigerators, MCE materials require to exhibit a large $\Delta S_{M}$, a high refrigerant capacity $(R C)$ as well as a tunable Curie temperatures $\left(T_{C}\right)$. Appropriate MCE materials consisting of multi-stage arrangement of MCE materials can provide tunable $T_{C}$, which is arranged in layered configuation according to their transition temperatures, will overcome the narrow temperature span within a single MCE materials in magnetic regenerators. ${ }^{4,5}$

Until now, several intermetallic compounds such as Gd$\mathrm{Si}-\mathrm{Ge},{ }^{6} \mathrm{La}-\mathrm{Ca}-\mathrm{Mn}-\mathrm{O},{ }^{7} \mathrm{Ni}-\mathrm{Mn}-\mathrm{Ga},{ }^{8} \mathrm{Mn}-\mathrm{Fe}-\mathrm{P}-\mathrm{As},{ }^{9}$ etc., display giant MCE near room temperature due to their first order magneto-structural phase transitions. However, they are unfortunately accompanied by large thermal and magnetic hysteresis, poor corrosion resistance, and mechanical instability upon magnetic field reversal, prohibiting their practical applications in cooling devices. ${ }^{10,11}$ In contrast, Febased metallic glasses (MGs) are well-known for their appealing combination of low materials cost, enhanced corrosion resistance, high electrical resistivity, and outstanding soft-magnetic properties. Besides, they also exhibit tunable $T_{C}$ together with a large $R C$ and modest $\Delta S_{M}$, making them

\footnotetext{
a) Authors to whom correspondence should be addressed. Electronic addresses: ctchang@nimte.ac.cn and dujun@nimte.ac.cn. Tel.: +86-57486685027. Fax: +86-574-87911392.
}

good candidates as near room-temperature magnetic refrigerants. ${ }^{12-20}$ Recent studies show that small additions of $\mathrm{Gd}$ to Fe-B-Cr amorphous alloys led to an increase in $T_{C}$, while light $\mathrm{RE}$ additions, such as $\mathrm{La}$ and $\mathrm{Ce}$, led to almost unchanged, or decrease in $T_{C}$, respectively. ${ }^{16,21}$ The $\mathrm{Fe}_{79} \mathrm{~B}_{12} \mathrm{Cr}_{8} \mathrm{Gd}_{1}$ and $\mathrm{Fe}_{79} \mathrm{~B}_{12} \mathrm{Cr}_{8} \mathrm{La}_{1}$ alloys were observed to present larger $R C$ than the well-known $\mathrm{Gd}_{5} \mathrm{Ge}_{1.9} \mathrm{Si}_{2} \mathrm{Fe}_{0.1}$ alloy. ${ }^{10}$ These findings imply that it is of significant to investigate the influence of RE addition on the MCE of Fe-based MGs. However, there is still a lack of systematic study of the $T_{C}$ dependence upon doping heavy RE and their consequences in the evolution of the MCE for Fe-based MGs. Moreover, most materials reported in literatures are limited to amorphous ribbons due to the necessity of a high cooling rate to form an amorphous phase, while only a few works report on the MCE of Fe-based bulk metallic glasses (BMGs). ${ }^{12,20}$ Fe-based BMGs with high glass-forming ability allow the fabrication of fully amorphous devices with more intricate and useful shapes by mold casting or selective laser melting. They are not only much easier to fabricate BMGs but also have excellent mechanical properties and corrosion resistance, as compared to the amorphous ribbons and powders.

It has been found that $\mathrm{Nb}$ is a better glass-forming element compared with $\mathrm{Cr}$ for Fe-B-based alloys. ${ }^{22}$ Based on this result, we had recently successfully developed a series of heavy RE doped Fe-B-Nb-based BMGs, which showed larger glass-forming ability (cylinders with up to $6.5 \mathrm{~mm}$ in diameter) than the Fe-B-Cr-based amorphous alloys, combined with good soft-magnetic and mechanical properties. $^{23,24}$ These features favor their application as magnetic refrigerants. Besides, taking into account the different influences of the type of RE element and its doping concentration on $T_{C}$ and MCE for Fe- ${ }^{16,21}$ and RE-based ${ }^{25,26}$ BMGs, the aim of this work is to study the effect of heavy RE elements addition on the $T_{C}$ and MCE of the Fe-RE-B-Nb $(\mathrm{RE}=\mathrm{Gd}$, 


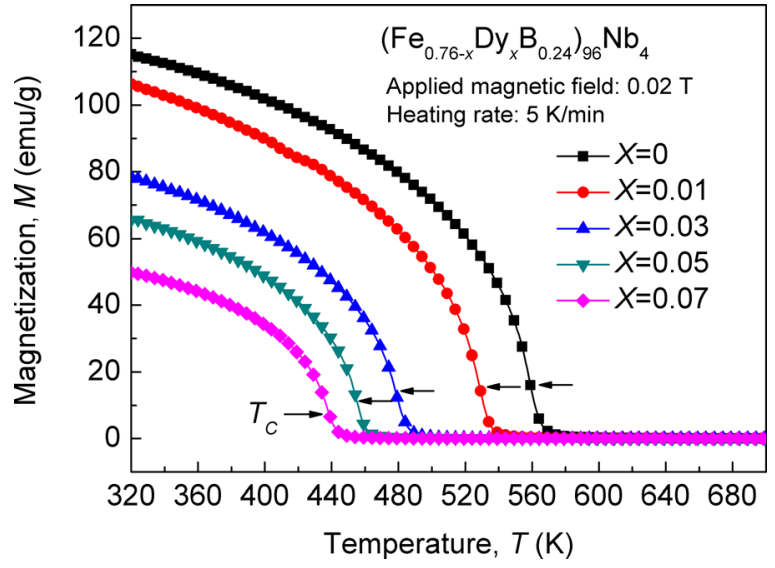

FIG. 1. Thermomagnetic measurements of $\left(\mathrm{Fe}_{0.76-x} \mathrm{Dy}_{x} \mathrm{~B}_{0.24}\right)_{96} \mathrm{Nb}_{4}(x=0$, $0.01,0.03,0.05$, and 0.07) BMGs under an applied magnetic field of $0.02 \mathrm{~T}$. Arrows mark the Curie temperatures of the samples.

Dy and Ho) BMGs. The present work shows that the $T_{C}$ of the Fe-RE-B-Nb BMGs can be tuned in a large temperature range not only by alloying appropriate amount of RE concentration but also by doping different RE elements.

\section{EXPERIMENTAL}

Buttons with nominal compositions of $\left(\mathrm{Fe}_{0.71} \mathrm{RE}_{0.05}\right.$ $\left.\mathrm{B}_{0.24}\right)_{96} \mathrm{Nb}_{4}(\mathrm{RE}=\mathrm{Gd}$ and $\mathrm{Ho})$ and $\left(\mathrm{Fe}_{0.76-x} \mathrm{Dy}_{x} \mathrm{~B}_{0.24}\right)_{96} \mathrm{Nb}_{4}$ ( $x=0,0.01,0.03,0.05$, and 0.07 at. \%) were prepared by arc melting the mixtures of high-purity elements (Fe: 99.99 wt. \%, Gd: 99.95 wt. \%, Dy: 99.9 wt. \%, Ho: 99.95 wt. \%, B: 99.5 wt. \%, $\mathrm{Nb}$ : 99.99 wt. \% purity) under an argon atmosphere. BMG rods with diameters up to $5.5 \mathrm{~mm}$ were obtained by copper mold casting, and subsequently crushed into smaller pieces prior to magnetic properties measurement. Magnetic properties were measured by a SQUID magnetometer (MPMS, Quantum $\left.\operatorname{Design}^{\circledR}\right)$. $T_{C}$ was calculated from the thermo-magnetization curves (M versus $\mathrm{T}$ ) under a field of $0.02 \mathrm{~T} . \Delta S_{M}$ was determined from isothermal $\mathrm{M} \sim \mathrm{H}$ curves at various temperatures with a maximum applied field of $1.5 \mathrm{~T}$ according to Maxwell equation: $^{27} \quad \Delta S_{M}=\int_{0}^{\mathrm{H}}(\partial M / \partial T)_{H} d H . R C$ was evaluated by $R C_{F W H M}=\left|\Delta S_{M}^{\mathrm{pk}}\right| \times \delta T_{F W H M}$, where $\left|\Delta S_{M}^{\mathrm{pk}}\right|$ is the maximum magnetic entropy change, and $\delta T_{F W H M}$ is the full width at half maximum of the peak. Further details about BMG synthesis, thermal stability, microstructural, magnetic and mechanical characterizations are given in Ref. 23.

\section{RESULTS AND DISCUSSION}

Fig. 1 shows the thermomagnetic measurements carried on the $\left(\mathrm{Fe}_{0.76-x} \mathrm{Dy}_{x} \mathrm{~B}_{0.24}\right)_{96} \mathrm{Nb}_{4}(x=0,0.01,0.03,0.05$, and $0.07)$ BMGs. The values of $T_{C}$ have been determined by the inflection point of the thermomagnetic curves (marked with arrows in Fig. 1). The $T_{C}$ of the base alloy is $559 \mathrm{~K}$ and has been regulated over large temperature range with increasing Dy doping content. As shown in Fig. 1 and Table I, the values of the $T_{C}$ for $x=0,0.01,0.03,0.05$, and 0.07 are 559, $528,478,455$, and $437 \mathrm{~K}$, respectively. It should be noted that the substitution of $\mathrm{Gd}$ for $\mathrm{Fe}$ in Fe-B-Cr MGs makes the $T_{C}$ shift to higher temperatures, which is an opposite trend to the Fe-B-Nb MGs. ${ }^{21}$ One possible reason is that although the magnitude of $T_{C}$ decreases continuously when substituting $\mathrm{RE}$ for Fe due to the antiferromagnetic coupling between RE and Fe moments and the dilution of the magnetic coupling by doping RE elements, ${ }^{28}$ the addition of $\mathrm{Gd}$ into the $\mathrm{Cr}$ containing alloy introduces a strong ferromagnetic coupling between $\mathrm{Gd}$ and $\mathrm{Cr}$ atoms, ${ }^{29}$ which increases the exchange energy of Fe-B-Cr MGs. On the contrary, there is just negligible exchange interaction between the ferromagnetic $\mathrm{Gd}$ and paramagnetic $\mathrm{Nb}$ atoms. ${ }^{30,31}$ Thus, the introduction of $\mathrm{Gd}$ into the Nb-containing series only reduces the exchange interactions between Fe atoms. From these results, the transition metal species of the starting alloy play a crucial role for

TABLE I. Maximum glass-forming diameter, ${ }^{24}$ Curie temperature, peak temperature of maximum entropy change, peak entropy change, and refrigerant capacity of Fe-RE-B-Nb in a field change of $1.5 \mathrm{~T}$. Data for the recently developed Fe-based amorphous alloys (measured under the same experimental conditions) are given for comparison.

\begin{tabular}{|c|c|c|c|c|c|c|}
\hline Nominal composition & $\begin{array}{c}\Phi \\
(\mathrm{mm})\end{array}$ & $\begin{array}{c}T_{C} \\
(\mathrm{~K})\end{array}$ & $\begin{array}{l}T_{\mathrm{pk}} \\
(\mathrm{K})\end{array}$ & $\begin{array}{c}\left|\Delta S_{M}^{\mathrm{pk}}\right| \\
\left(\mathrm{Jkg}^{-1} \mathrm{~K}^{-1}\right)\end{array}$ & $\begin{array}{c}R C_{F W H M} \\
\left(\mathrm{Jkg}^{-1}\right)\end{array}$ & Reference \\
\hline$\left(\mathrm{Fe}_{0.76} \mathrm{Dy}_{0} \mathrm{~B}_{0.24}\right)_{96} \mathrm{Nb}_{4}$ & - & 559 & 563 & 1.51 & 121 & This work \\
\hline$\left(\mathrm{Fe}_{0.75} \mathrm{Dy}_{0.01} \mathrm{~B}_{0.24}\right)_{96} \mathrm{Nb}_{4}$ & 0.5 & 528 & 534 & 1.34 & 117 & This work \\
\hline$\left(\mathrm{Fe}_{0.73} \mathrm{Dy}_{0.03} \mathrm{~B}_{0.24}\right)_{96} \mathrm{Nb}_{4}$ & 3.5 & 478 & 490 & 1.24 & 112 & This work \\
\hline$\left(\mathrm{Fe}_{0.71} \mathrm{Dy}_{0.05} \mathrm{~B}_{0.24}\right)_{96} \mathrm{Nb}_{4}$ & 5.5 & 455 & 460 & 1.11 & 78 & This work \\
\hline$\left(\mathrm{Fe}_{0.69} \mathrm{Dy}_{0.07} \mathrm{~B}_{0.24}\right)_{96} \mathrm{Nb}_{4}$ & 3 & 437 & 435 & 1.07 & 70 & This work \\
\hline$\left(\mathrm{Fe}_{0.71} \mathrm{Gd}_{0.05} \mathrm{~B}_{0.24}\right)_{96} \mathrm{Nb}_{4}$ & 3.5 & 488 & 493 & 1.10 & 78 & This work \\
\hline$\left(\mathrm{Fe}_{0.71} \mathrm{Ho}_{0.05} \mathrm{~B}_{0.24}\right)_{96} \mathrm{Nb}_{4}$ & 5 & 440 & 439 & 1.11 & 85 & This work \\
\hline $\mathrm{Fe}_{85} \mathrm{Zr}_{10} \mathrm{~B}_{5}$ & - & 300 & & 1.39 & & 14 \\
\hline $\mathrm{Fe}_{70} \mathrm{Mn}_{10} \mathrm{~B}_{20}$ & - & 438 & & 1 & 117 & 15 \\
\hline $\mathrm{Fe}_{79} \mathrm{La}_{1} \mathrm{Cr}_{8} \mathrm{~B}_{12}$ & - & & 355 & 1.1 & 130 & 16 \\
\hline $\mathrm{Fe}_{79} \mathrm{Ce}_{1} \mathrm{Cr}_{8} \mathrm{~B}_{12}$ & - & & 325 & 1.06 & 118 & 16 \\
\hline $\mathrm{Fe}_{78} \mathrm{Nb}_{8} \mathrm{~B}_{14}$ & - & & 374 & 1.2 & & 19 \\
\hline $\mathrm{Fe}_{65} \mathrm{Mn}_{15} \mathrm{P}_{10} \mathrm{~B}_{7} \mathrm{C}_{3}$ & - & 292 & 295 & 0.91 & 118 & 20 \\
\hline $\mathrm{Fe}_{79} \mathrm{Gd}_{1} \mathrm{Cr}_{8} \mathrm{~B}_{12}$ & - & & 355 & 1.42 & 153 & 21 \\
\hline $\mathrm{Fe}_{75} \mathrm{Gd}_{5} \mathrm{Cr}_{8} \mathrm{~B}_{12}$ & - & & 500 & 0.95 & 73 & 21 \\
\hline $\mathrm{Fe}_{88} \mathrm{Zr}_{7} \mathrm{~B}_{4} \mathrm{Cu}_{1}$ & - & 287 & 295 & 1.32 & 166 & 35 \\
\hline $\mathrm{Fe}_{71.5} \mathrm{Co}_{8.25} \mathrm{Ni}_{8.25} \mathrm{Zr}_{7} \mathrm{~B}_{4} \mathrm{Cu}_{1}$ & - & 541 & & 1.98 & 130 & 35 \\
\hline
\end{tabular}




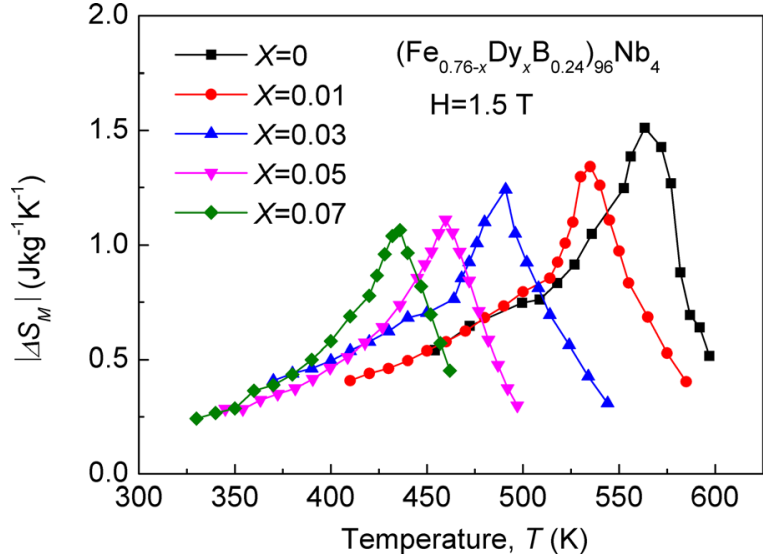

FIG. 2. Temperature dependence of magnetic entropy change of the $\left(\mathrm{Fe}_{0.76-x} \mathrm{Dy}_{x} \mathrm{~B}_{0.24}\right)_{96} \mathrm{Nb}_{4}(x=0,0.01,0.03,0.05$, and 0.07) BMGs under an applied field of $1.5 \mathrm{~T}$.

evaluating the $T_{C}$ of heavy RE doped Fe-based BMGs because they determine the starting point and evolution for each doping series. ${ }^{12-14,16,21}$ The decrease of $T_{C}$ with increasing RE content in Fe-B-Nb-based BMGs reveals that the room-temperature $T_{C}$ values can be achieved upon alloying a sufficient amount of RE content.

The temperature dependence of magnetic entropy change of the $\left(\mathrm{Fe}_{0.76-x} \mathrm{Dy}_{x} \mathrm{~B}_{0.24}\right)_{96} \mathrm{Nb}_{4}(x=0,0.01,0.03$, 0.05 , and 0.07) BMGs is illustrated in Fig. 2.The $\left|\Delta S_{M}^{\mathrm{pk}}\right|$ moderately decreases with increasing Dy content, reaching typical values around $1.2 \mathrm{Jkg}^{-1} \mathrm{~K}^{-1}$. It is known that the $\mathrm{Fe}$ moment of a given Fe-based alloy decreases upon alloying with heavy RE element due to the hybridization of the $\mathrm{Fe} 3 \mathrm{~d}$ and the RE 5d states. ${ }^{28,32}$ According to Annouar et al., ${ }^{32}$ the substitution of Fe by Dy in Fe-Dy-B MGs increased the $5 \mathrm{~d}-3 \mathrm{~d}$ hybridization. In accordance with that, the decreasing $\left|\Delta S_{M}^{\mathrm{pk}}\right|$ with increasing Dy content mainly stems from the decrease in Fe moment of this alloy series.

It has been recently reported that the addition of $\sim 5$ at. $\%$ heavy $\mathrm{RE}$ to the $\mathrm{Fe}-\mathrm{B}-\mathrm{Nb}$ alloy can remarkably improve the glass-forming ability without significantly deteriorating the

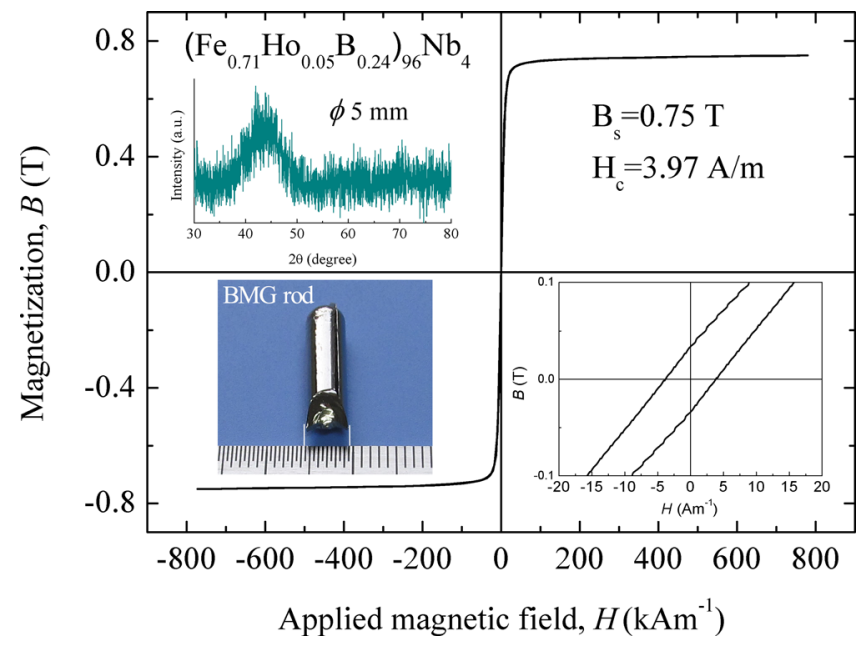

FIG. 3. $B-H$ hysteresis curves measured with VSM and B-H loops (right inset) showed $\mathrm{B}-\mathrm{H}$ loop tracer of the $\left(\mathrm{Fe}_{0.71} \mathrm{Ho}_{0.05} \mathrm{~B}_{0.24}\right)_{96} \mathrm{Nb}_{4} \mathrm{BMG}$. Left inset shows the outer morphology of the $5 \mathrm{~mm}$ cylindrical rod and its XRD pattern.

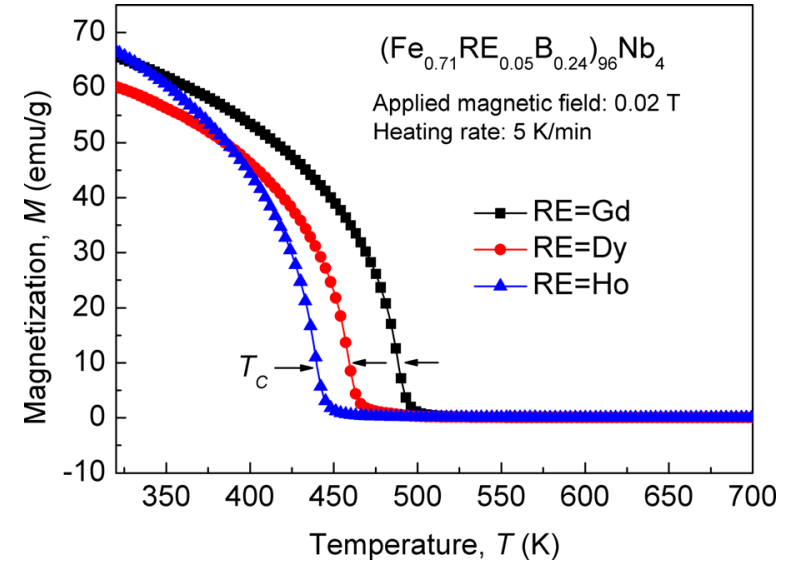

FIG. 4. Temperature dependence of magnetization of $\left(\mathrm{Fe}_{0.71} \mathrm{RE}_{0.05} \mathrm{~B}_{0.24}\right){ }_{96} \mathrm{Nb}_{4}$ $(\mathrm{RE}=\mathrm{Gd}, \mathrm{Dy}, \mathrm{Ho}) \mathrm{BMGs}$ under an applied magnetic field of $0.02 \mathrm{~T}$. Arrows mark the Curie temperatures of the samples.

soft-magnetic properties. ${ }^{21}$ An example is shown in Fig. 3, wherein the XRD pattern of the cast $\left(\mathrm{Fe}_{0.71} \mathrm{Ho}_{0.05} \mathrm{~B}_{0.24}\right)_{96} \mathrm{Nb}_{4}$ alloy rod exhibits only a broad diffraction peak without any detectable sharp Bragg peak, indicating the fully amorphous nature of the $5 \mathrm{~mm}$ cylindrical rod (see the left inset in Fig. 3). Meanwhile, the alloy presents good soft-magnetic properties, i.e., high saturation magnetization of $0.75 \mathrm{~T}$ and low coercive force of $3.97 \mathrm{Am}^{-1}$ (see right inset of Fig. 3). The small magnetic hysteresis is considered to be a very beneficial characteristic for magnetic refrigerant application. Accordingly, the dependence of $T_{C}$ and MCE on the type of heavy RE doping element in these large glass formers was also evaluated.

Fig. 4 shows the temperature dependence of magnetization of the $\left(\mathrm{Fe}_{0.71} \mathrm{RE}_{0.05} \mathrm{~B}_{0.24}\right)_{96} \mathrm{Nb}_{4}(\mathrm{RE}=\mathrm{Gd}$, Dy, Ho) BMGs under an applied magnetic field of 200 Oe. As shown in Fig. 4 and Table I, the $T_{C}$ of the $\left(\mathrm{Fe}_{0.71} \mathrm{RE}_{0.05} \mathrm{~B}_{0.24}\right)_{96} \mathrm{Nb}_{4}(\mathrm{RE}=\mathrm{Gd}$, Dy, Ho) BMGs are 488,455 , and $440 \mathrm{~K}$, respectively. It is known that the values of $T_{C}$ in a given lanthanide compound series are related to the deGennes factor $(F)$, which can be expressed as: ${ }^{33} F=[J(J+1)+S(S+1)-L(L-1)] / 4 J(J+1)$, where $J$ is the total orbital quantum number, $S$ is the spin quantum number, and $L$ is the orbital angular momentum quantum number. According to the formula, the deGennes factors of $\mathrm{Gd}$,

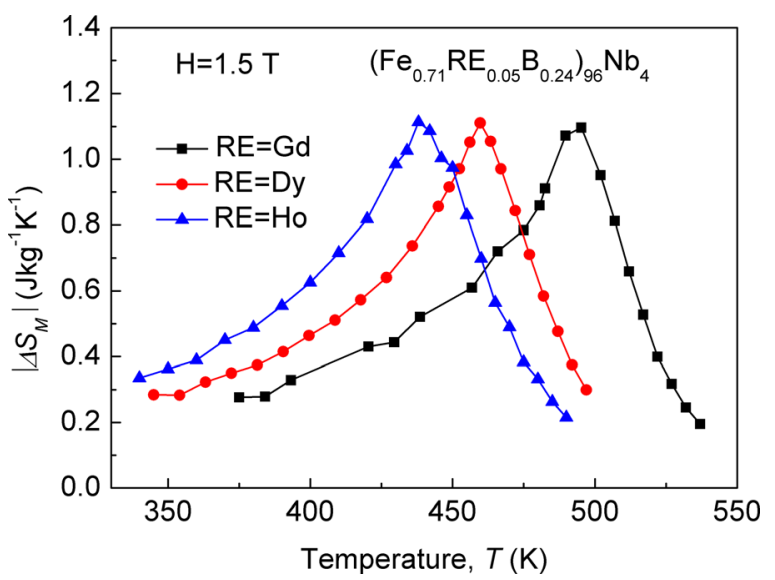

FIG. 5. Temperature dependence of magnetic entropy change of $\left(\mathrm{Fe}_{0.71} \mathrm{RE}_{0.05} \mathrm{~B}_{0.24}\right)_{96} \mathrm{Nb}_{4}(\mathrm{RE}=\mathrm{Gd}$, Dy, Ho) BMGs under an applied magnetic field of $1.5 \mathrm{~T}$. 
Dy, and Ho are 15.76, 7.07, and 4.5, respectively. Generally, the $T_{C}$ tends to follow the deGennes factor. ${ }^{33}$ Thus, the $\mathrm{Gd}$ doped alloy exhibits the largest $T_{C}$, while the Ho doped alloy displays the lowest $T_{C}$. Therefore, the magnetic ordering temperature of Fe-based BMGs can be easily tuned in a large temperature range not only by adding different heavy RE but also by its appropriate alloying concentration.

Fig. 5 presents the temperature dependence of magnetic entropy change of the $\left(\mathrm{Fe}_{0.71} \mathrm{RE}_{0.05} \mathrm{~B}_{0.24}\right)_{96} \mathrm{Nb}_{4}(\mathrm{RE}=\mathrm{Gd}$, Dy, Ho) BMGs under an applied magnetic field of $1.5 \mathrm{~T}$, wherein the maximum magnetic entropy change $\left(\left|\Delta S_{M}^{\mathrm{pk}}\right|\right)$ are 1.10 $\mathrm{Jkg}^{-1} \mathrm{~K}^{-1}$ for $\mathrm{RE}=\mathrm{Gd}, 1.11 \mathrm{Jkg}^{-1} \mathrm{~K}^{-1}$ for $\mathrm{RE}=\mathrm{Dy}$, and $1.11 \mathrm{Jkg}^{-1} \mathrm{~K}^{-1}$ for $\mathrm{RE}=$ Ho. The most remarkable feature of the Fig. 5 is that $\left|\Delta S_{M}^{\mathrm{pk}}\right|$ remains constant, despite the shift in the temperature of the peak entropy change $\left(T_{\mathrm{pk}}\right)$. The observed constant value of $\left|\Delta S_{M}^{\mathrm{pk}}\right|$ is in agreement with the similar magnetic moment per transition metal in these three alloys (not shown). Thus, adding the same amount of different heavy RE elements to the Fe-RE-B-Nb BMGs can tune easily the $T_{C}$ without reducing the $\left|\Delta S_{M}^{\mathrm{pk}}\right|$.

Table I summaries the maximum glass-forming diameter $(\Phi), T_{C}, T_{\mathrm{pk}},\left|\Delta S_{M}^{\mathrm{pk}}\right|$, and $R C$ of the studied alloys. For comparison, the magnetic and magnetocaloric properties of recently developed Fe-based MGs are also listed in Table I (the calculation methods and experimental conditions are the same). It is observed that the evolution of $T_{\mathrm{pk}}$ is in agreement with the trend of $T_{C} \cdot{ }^{34}$ As the RE content increases, the $R C$ of all samples decreases, which could be ascribed to the reduction in $\left|\Delta S_{M}^{\mathrm{pk}}\right|$ since $\delta T_{F W H M}$ increases with a small addition of RE ( $R C$ is derived from the product of $\left|\Delta S_{M}^{\mathrm{pk}}\right|$ and $\left.\delta T_{F W H M}\right)$. Moreover, in spite of the $T_{C}$ can be tuned by adding different RE elements, there is no significant difference in the $R C$ of the alloys. This indicates an effective route towards the optimization of $T_{C}$ of MCE material without a detrimental effect on its MCE response. The studied alloys exhibit $\left|\Delta S_{M}^{\mathrm{pk}}\right|$ and $R C$ values which are comparable to those reported recently for the $\mathrm{Fe}$-rich amorphous ribbons $(R C$ is larger than those of $\left.\mathrm{Gd}_{5} \mathrm{Ge}_{1.9} \mathrm{Si}_{2} \mathrm{Fe}_{0.1}\right){ }^{16,21,35}$ Most importantly, the former was prepared as large-size bulk amorphous materials, while other amorphous alloys are incapable of being prepared as bulk form $(\Phi<0.5 \mathrm{~mm})$.

\section{CONCLUSIONS}

The magnetic properties and magnetocaloric effect of the Fe-RE-B-Nb ( $\mathrm{RE}=\mathrm{Gd}$, Dy, and Ho) BMGs were studied. The $T_{C}$ was easily tuned in a large temperature range of $120 \mathrm{~K}$ by varying heavy $\mathrm{RE}$ concentration as well as its species. Although $\left|\Delta S_{M}^{\mathrm{pk}}\right|$ and $R C$ of the BMG series decrease with increasing RE content due to the reduction of the $\mathrm{Fe}$ moment, those values for the alloys with different RE elements remain relatively constant, which are comparable to those of the recently reported $\mathrm{Fe}_{79} \mathrm{~B}_{12} \mathrm{Cr}_{8} \mathrm{Gd}_{1}$ and $\mathrm{Fe}_{79} \mathrm{~B}_{12} \mathrm{Cr}_{8} \mathrm{La}_{1}$ amorphous alloys. The tunable $T_{C}$, comparable MCE response, good soft-magnetic properties and excellent glass-forming ability of the heavy RE doped Fe-based BMGs are beneficial for preparing bulk magnetic refrigerants with a large temperature range.

\section{ACKNOWLEDGMENTS}

This work was supported by the Natural Science Foundation of Zhejiang Province Outstanding Youth Fund (Grant No. LR12E01001), the National Natural Science Foundation of China (Grant No. 51301188), the China Postdoctoral Science Foundation (Grant No. 2013M541804), the Ningbo Science and Technology Innovation Team (Grant Nos. 2011B82004 and 2012B81001).

${ }^{1}$ O. Gutfleisch, M. A. Willard, E. Bruck, C. H. Chen, S. G. Sankar, and J. P. Liu, Adv. Mater. 23, 821 (2011).

${ }^{2}$ V. Franco, J. S. Blazquez, B. Ingale, and A. Conde, Annu. Rev. Mater. Res. 42, 305 (2012).

${ }^{3}$ K. A. Gschneidner, V. K. Pecharsky, and A. O. Tsokol, Rep. Prog. Phys. 68, 1479 (2005).

${ }^{4}$ M. A. Richard, A. M. Rowe, and R. Chahine, J. Appl. Phys. 95, 2146 (2004).

${ }^{5}$ J. Y. Law, Ph.D. thesis, Nanyang Technological Univeristy, Singapore, 2012.

${ }^{6}$ V. K. Pecharsky and K. A. Gschneidner, Phys. Rev. Lett. 78, 4494 (1997).

${ }^{7}$ Z. B. Guo, Y. W. Du, J. S. Zhu, H. Huang, W. P. Ding, and D. Feng, Phys. Rev. Lett. 78, 1142 (1997).

${ }^{8}$ F. X. Hu, B. G. Shen, and J. R. Sun, Appl. Phys. Lett. 76, 3460 (2000).

${ }^{9}$ O. Tegus, E. Bruck, K. H. J. Buschow, and F. R. de Boer, Nature 415, 150 (2002).

${ }^{10}$ V. Provenzano, A. J. Shapiro, and R. D. Shull, Nature 429, 853 (2004).

${ }^{11}$ E. Bruck, J. Phys. D. Appl. Phys. 38, R381 (2005).

${ }^{12}$ V. Franco, J. M. Borrego, A. Conde, and S. Roth, Appl. Phys. Lett. 88, 132509 (2006).

${ }^{13}$ I. Skorvanek, J. Kovac, J. Marcin, P. Svec, and D. Janickovic, Mater. Sci. Eng. A 449-451, 460 (2007).

${ }^{14}$ Y. Y. Wang and X. F. Bi, Appl. Phys. Lett. 95, 262501 (2009).

${ }^{15}$ R. Caballero-Flores, V. Franco, A. Conde, and L. F. Kiss, J. Appl. Phys. 108, 073921 (2010).

${ }^{16}$ J. Y. Law, V. Franco, and R. V. Ramanujan, Appl. Phys. Lett. 98, 192503 (2011).

${ }^{17}$ J. J. Ipus, H. Ucar, and M. E. McHenry, IEEE. Trans. Magn. 47, 2494 (2011).

${ }^{18}$ V. Franco and A. Conde, Scr. Mater. 67, 594 (2012).

${ }^{19}$ A. Waske, B. Schwarz, N. Mattern, and J. Eckert, J. Magn. Magn. Mater. 329, 101 (2013).

${ }^{20}$ H. Y. Zhang, R. Li, T. Xu, F. M. Liu, and T. Zhang, J. Magn. Magn. Mater. 347, 131 (2013).

${ }^{21}$ J. Y. Law, R. V. Ramanujan, and V. Franco, J. Alloys Compd. 508, 14 (2010).

${ }^{22}$ W. Zhang, Y. Long, M. Imafuku, X. M. Wang, and A. Inoue, J. Metastat. Nanocryst. Mater. 24-25, 117 (2005).

${ }^{23}$ J. W. Li, W. M. Yang, D. Estévez, G. X. Chen, W. G. Zhao, Q. K. Man, Y. Y. Zhao, Z. D. Zhang, and B. L. Shen, Intermetallics 46, 85 (2014).

${ }^{24}$ J. W. Li, D. Estévez, K. M. Jiang, W. M. Yang, Q. K. Man, and C. T. Chang, "Electronic-structure origin of the glass-forming ability and magnetic properties in Fe-RE-B-Nb bulk metallic glasses," J. Alloys Compounds (unpublished).

${ }^{25}$ Q. Luo and W. H. Wang, J. Alloys Compd. 495, 209 (2010).

${ }^{26}$ J. T. Huo, D. Q. Zhao, H. Y. Bai, E. Axinte, and W. H. Wang, J. NonCryst. Solids 359, 1 (2013).

${ }^{27}$ T. Hashimoto, T. Numasawa, M. Shino, and T. Okada, Cryogenics 21, 647 (1981).

${ }^{28}$ K. H. J. Buschow, Rep. Prog. Phys. 40, 1179 (1977).

${ }^{29}$ H. S. Li, J. M. Cadogan, X. L. Zhao, and S. J. Campbell, Hyperfine. Interact. 94, 1891 (1994).

${ }^{30}$ A. Chrobak, V. Nosenko, G. Haneczok, L. Boichyshyn, B. Kotur, A. Bajorek, O. Zivotsky, and A. Hendrych, Mater. Chem. Phys. 130, 603 (2011).

${ }^{31}$ W. M. Yang, H. S. Liu, L. Xue, J. W. Li, C. C. Dun, J. H. Zhang, Y. C. Zhao, and B. L. Shen, J. Magn. Magn. Mater. 335, 172 (2013).

${ }^{32}$ F. Annouar, H. Lassri, M. Ayadi, M. Omri, M. Lassri, and R. Krishnan, J. Alloys Compd. 397, 42 (2005).

${ }^{33}$ J. K. A. Gschneidner, A. O. Pecharsky, and V. K. Pecharsky, Cryocoolers 12, 457 (2003).

${ }^{34}$ V. Franco, A. Conde, M. D. Kuz'min, and J. M. Romero-Enrique, J. Appl. Phys. 105, 07A917 (2009).

${ }^{35}$ R. Caballero-Flores, V. Franco, A. Conde, K. E. Knipling, and M. A. Willard, Appl. Phys. Lett. 96, 182506 (2010). 